\title{
Reduced myocardial perfusion in post renal transplant population is not associated with aortic stiffness
}

\author{
Susie F Parnham ${ }^{4,1}$, Suchi Grover ${ }^{1,3}$, Craig Bradbrook ${ }^{3 *}$, Darryl Leong ${ }^{3}$, Carmine De Pasquale ${ }^{1,4}$, Jonathan Gleadle $e^{2,4}$, \\ Joseph Selvanayagam ${ }^{1,4}$
}

From 17th Annual SCMR Scientific Sessions

New Orleans, LA, USA. 16-19 January 2014

\section{Background}

Objective: The purpose of this study was to assess central (aortic) vascular dysfunction in post renal transplant patients by high-resolution cardiovascular magnetic resonance imaging (CMR). Background: Renal transplant recipients are at increased risk of cardiovascular $(\mathrm{CV})$ disease. The cardiac phenotype in post-transplant recipients is not well defined. A recent study suggested myocardial perfusion is impaired in renal transplant patients irrespective of the degree of left ventricular hypertrophy [1].We hypothesized that post transplant patients have persistently increased aortic stiffness, and that it could be correlated with reduced myocardial perfusion.

\section{Methods}

Methods: Twenty-five asymptomatic renal transplant patients (RT) and 17 hypertensive controls (HT) underwent CMR scanning at $1.5 \mathrm{~T}$. Myocardial function, late enhancement, aortic pulse wave velocity and first-pass perfusion at rest and stress was performed. Myocardial Perfusion Reserve Index (MPRI) was calculated as the ratio of hyperemic to resting myocardial blood flow by dividing the myocardial perfusion at stress by rest perfusion (corrected to rate pressure product). Pulse wave velocity $(\mathrm{PWV})$ was calculated as the ratio between the distance and time from ascending aorta to descending aorta at the level of main pulmonary artery. Statistical analyses were performed using mixed effects modelling for MPRI and linear regression for relationship between MPRI and PWV.

\section{Results}

Results: Baseline clinical characteristics were similar for RT and HT control groups. Mean inter-ventricular septal thickness and LV mass indexed to body surface area were similar in both RT cases and HT controls. MPRI was significantly lower in the RT group compared to the HT group (1.36 \pm 0.52 vs $2.06 \pm 0.59, \mathrm{p}=0.0004)$, globally and in all three coronary artery territories[1]. Aortic Pulse Wave Velocity (PWV) is not significantly different between RT and HT group (3.46 \pm 0.51 vs $5.21 \pm 1.07, \mathrm{p}=$ $0.14)$. There is no correlation between aortic pulse wave velocity and MPRI ( $\mathrm{r} 2=0.0026$, coeff $=0.18, \mathrm{p}=0.83$ ).

\section{Conclusions}

Conclusions: In our cohort population, there is no evidence of increased aortic stiffness in post renal transplant patients compared to hypertensive patients. Although these patients demonstrate impaired myocardial perfusion reserve, this is not correlated with increased aortic stiffness.

\section{Funding}

None.

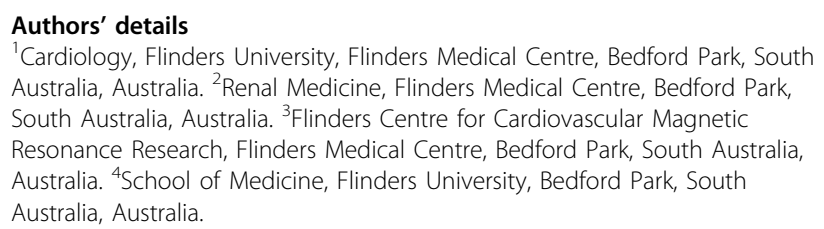

Authors' details

Cardiology, Flinders University, Flinders Medical Centre, Bedford Park, South Australia, Australia. ${ }^{2}$ Renal Medicine, Flinders Medical Centre, Bedford Park, South Australia, Australia. ${ }^{3}$ Flinders Centre for Cardiovascular Magnetic Australia. ${ }^{4}$ School of Medicine, Flinders University, Bedford Park, South Australia, Australia. 
Published: 16 January 2014

\section{Reference}

1. Parnham S, Grover S, Bradbrook C, Srinivasan G, DePasquale C, Woodman R, Gleadle J, Selvanayagam J: Myocardial Perfusion is Impaired in Asymptomatic Patients Post Renal Transplantation. Journal of Cardiovascular Magnetic Resonance 2013, 15(Supple 1):E68.

doi:10.1186/1532-429X-16-S1-P226

Cite this article as: Parnham et al.: Reduced myocardial perfusion in post renal transplant population is not associated with aortic stiffness. Journal of Cardiovascular Magnetic Resonance 2014 16(Suppl 1):P226.

Submit your next manuscript to BioMed Central and take full advantage of:

- Convenient online submission

- Thorough peer review

- No space constraints or color figure charges

- Immediate publication on acceptance

- Inclusion in PubMed, CAS, Scopus and Google Scholar

- Research which is freely available for redistribution

Submit your manuscript at www.biomedcentral.com/submit
C Biomed Central 